\title{
Notes on the vocalizations of Long-billed Gnatwren (Ramphocaenus melanurus)
}

Peter Boesman

In the following we briefly analyze and compare voice of the different races of Long-billed Gnatwren (Ramphocaenus melanurus). We also try to quantify the extent of any vocal differences using the criteria proposed by Tobias et al. (2010), as a support for taxonomic review. We have made use of sound recordings available on-line from Xeno Canto (XC).

A comparison of song per race, illustrated with sonograms:

Group 1: rufiventris, ardeleo, panamensis and griseodorsalis (northern races) rufiventris

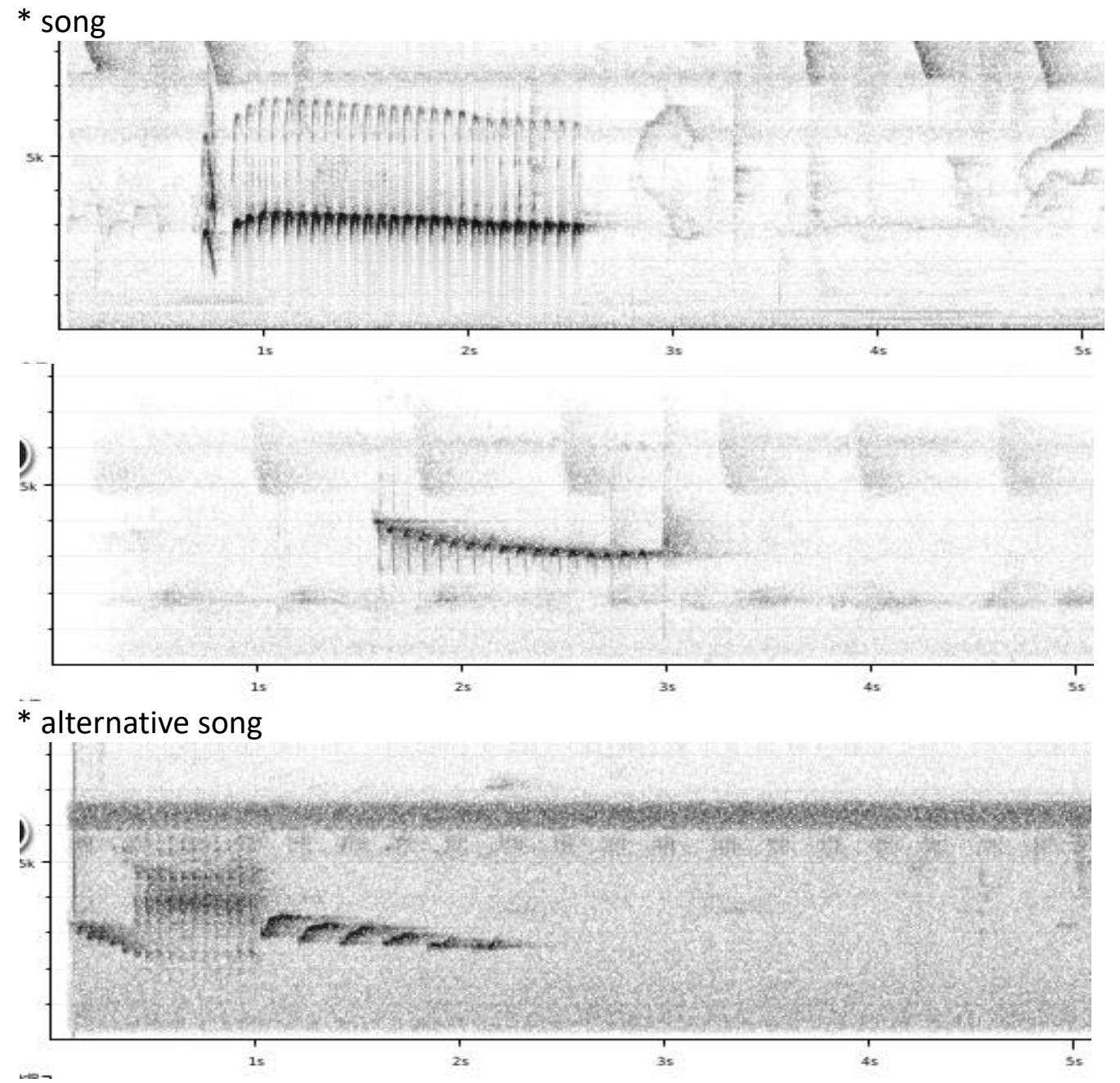


HANDBOOK OF THE

Alve

ORNITHOLOGICAL NOTES

ardeleo
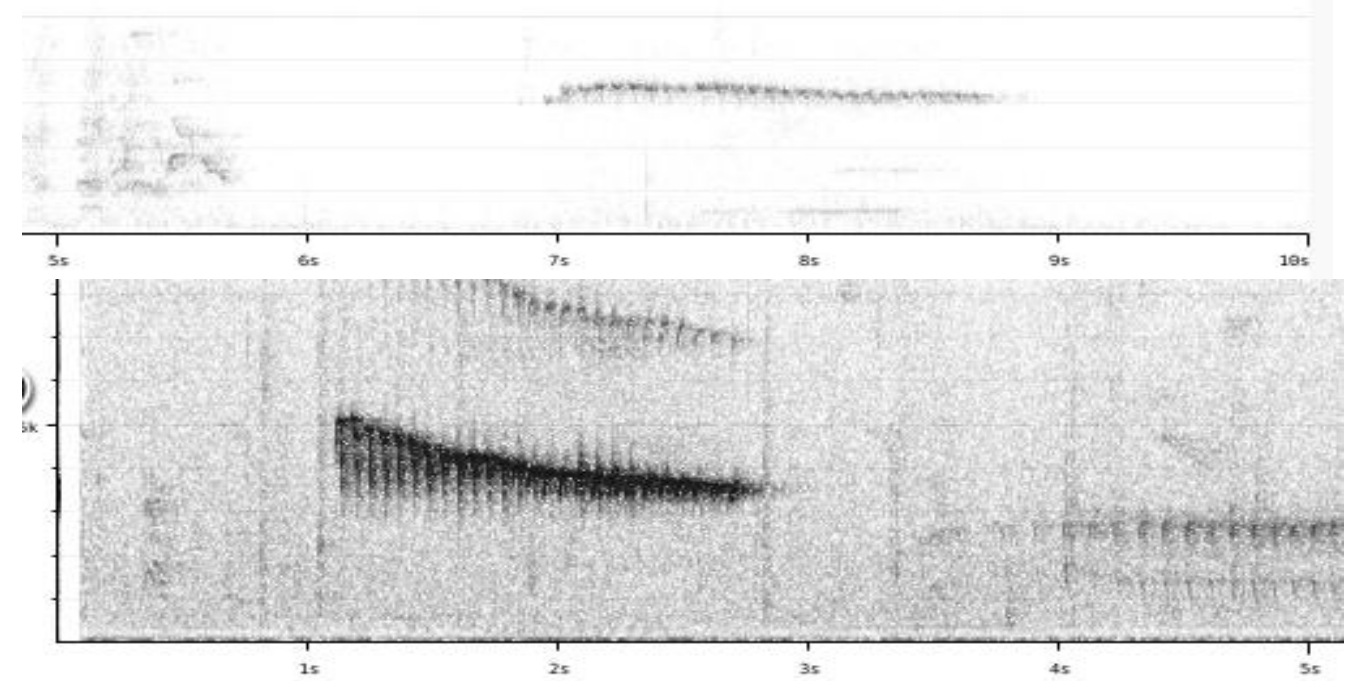

panamensis

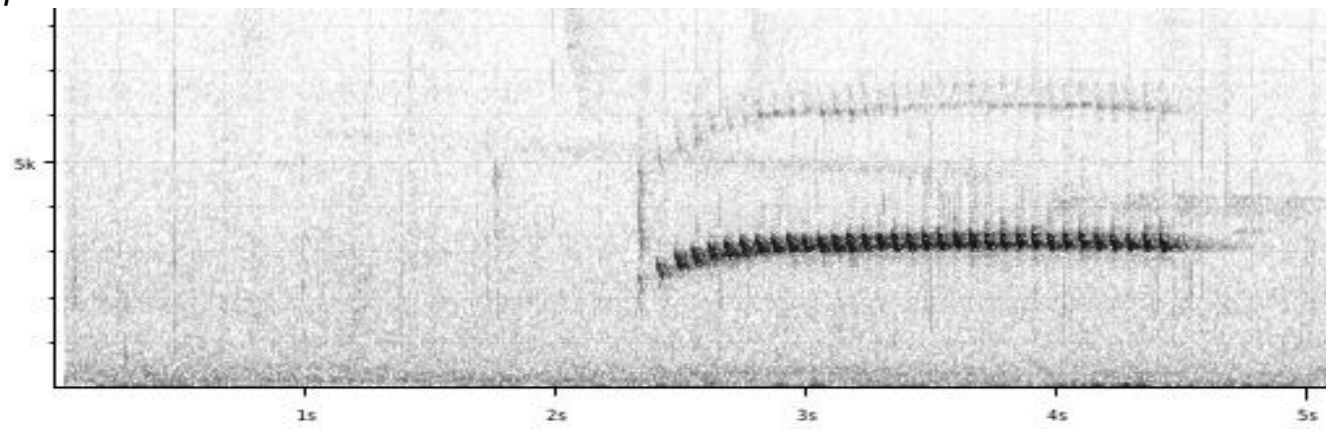

griseodorsalis

* song

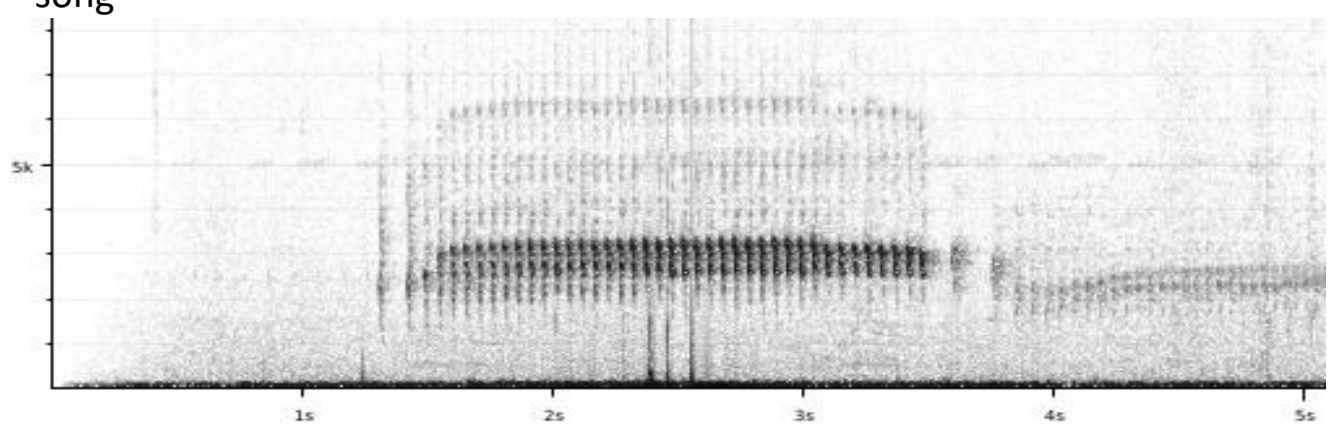

* alternative song

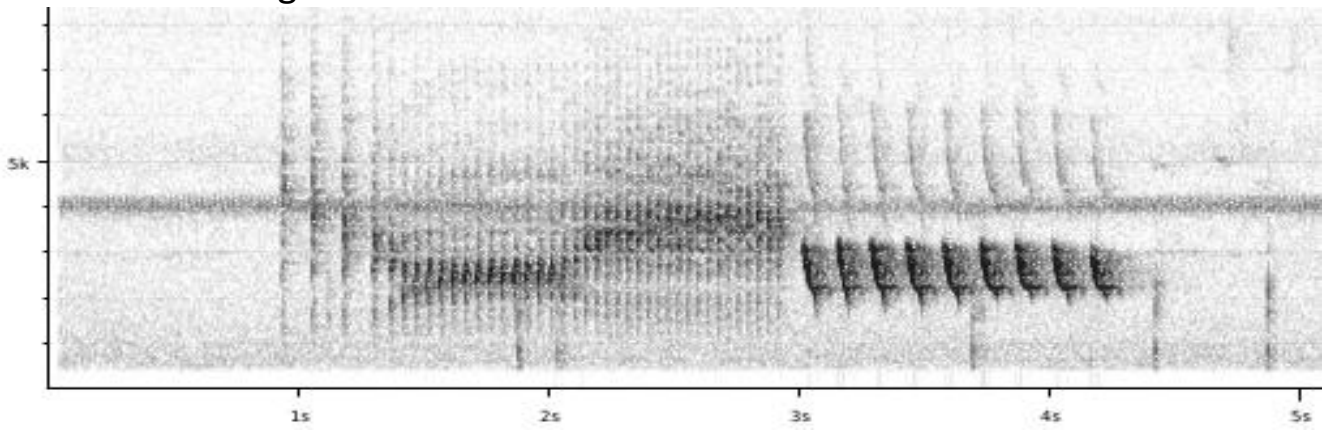




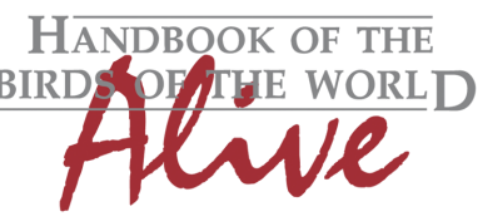

\section{ORNITHOLOGICAL NOTES}

Group 2: sanctaemartae, pallidus, trinitatis, albiventris, duidae, badius, amazonum, austerus and melanurus.

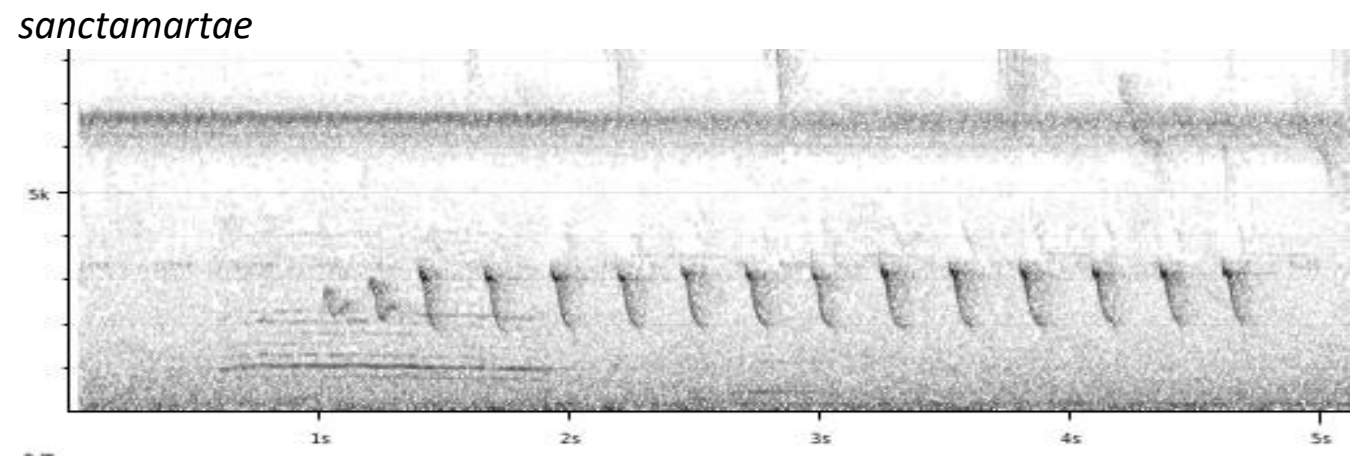

pallidus
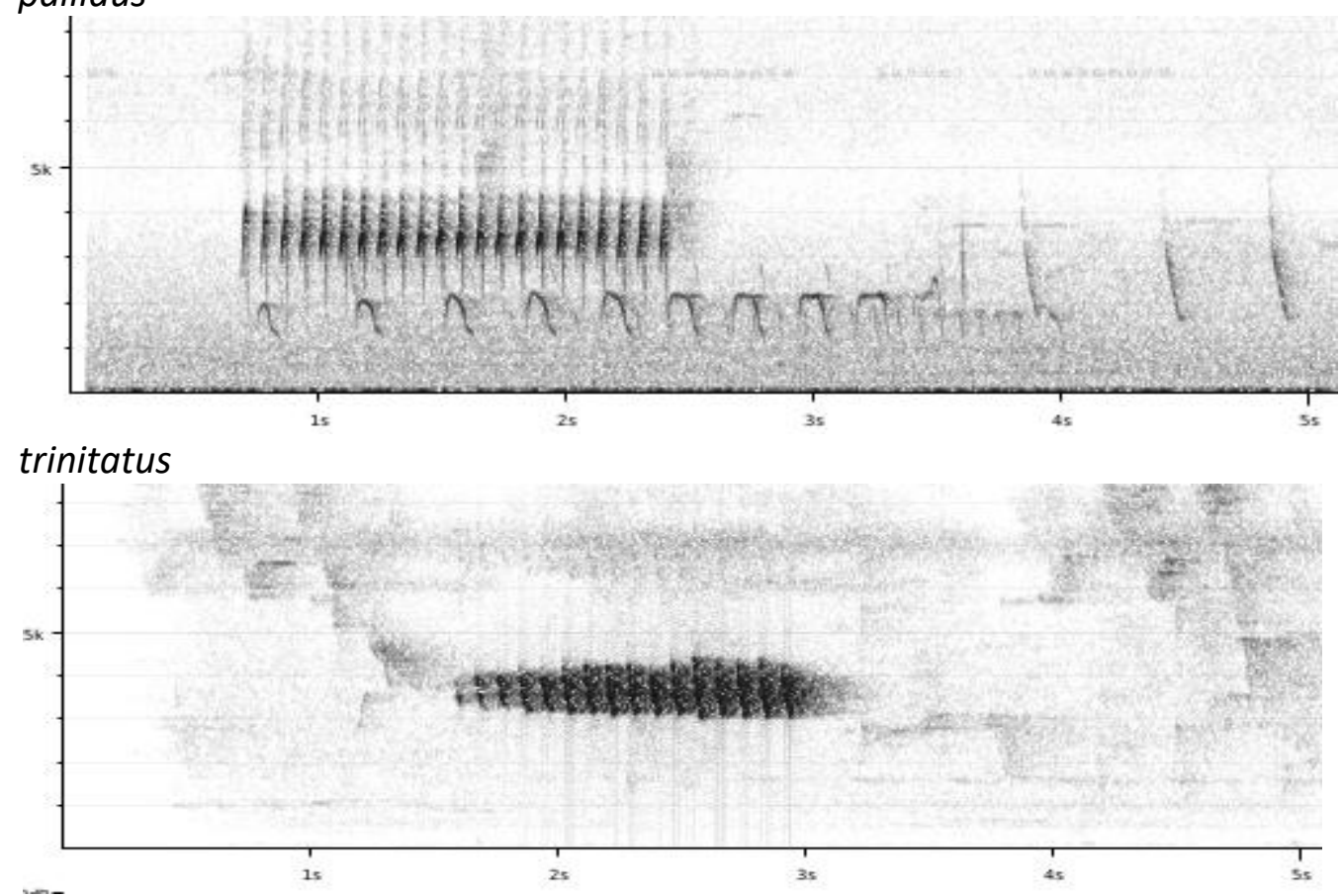

albiventris
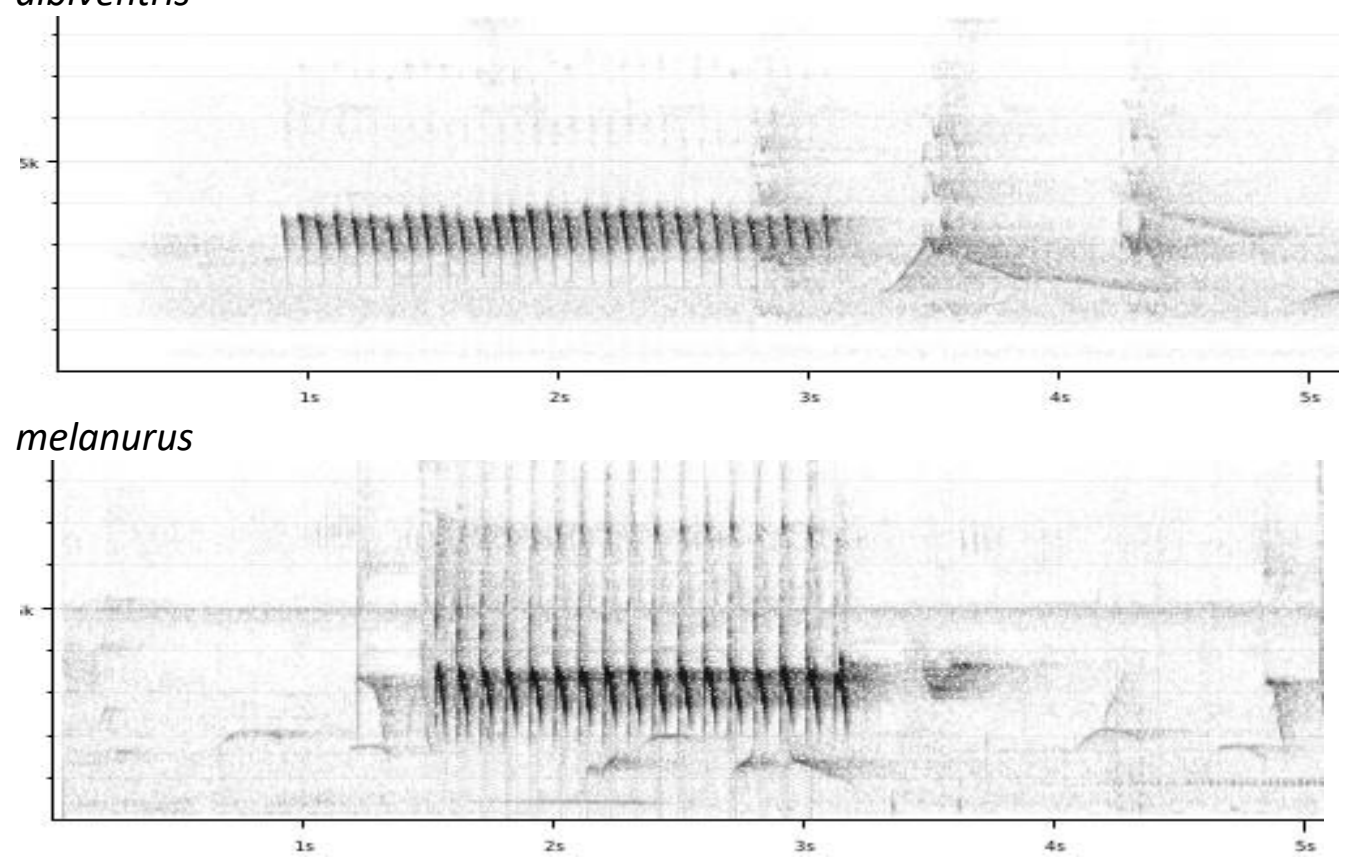


\section{HANDBOOK OF THE \\ BIRDSPF THE WORLD \\ Aluve}

\section{ORNITHOLOGICAL NOTES}

Group 3: obscurus and sticturus.

obscurus

Exact distribution of this taxon seems to be uncertain. The following examples are presumably this race:

Portillo, S of Iberia, Madre de Dios, Peru

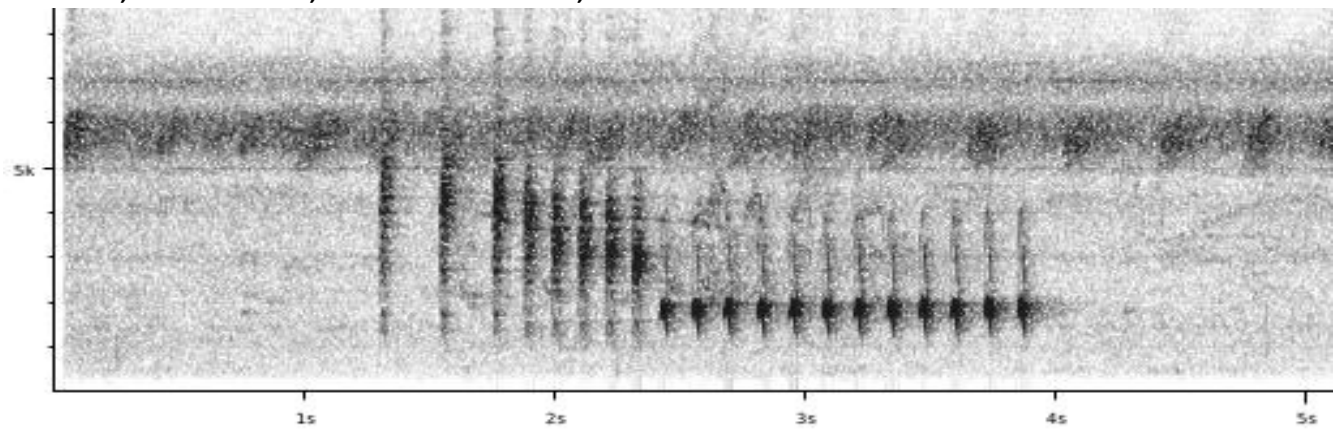

Cuzco area (Manu rd), Peru
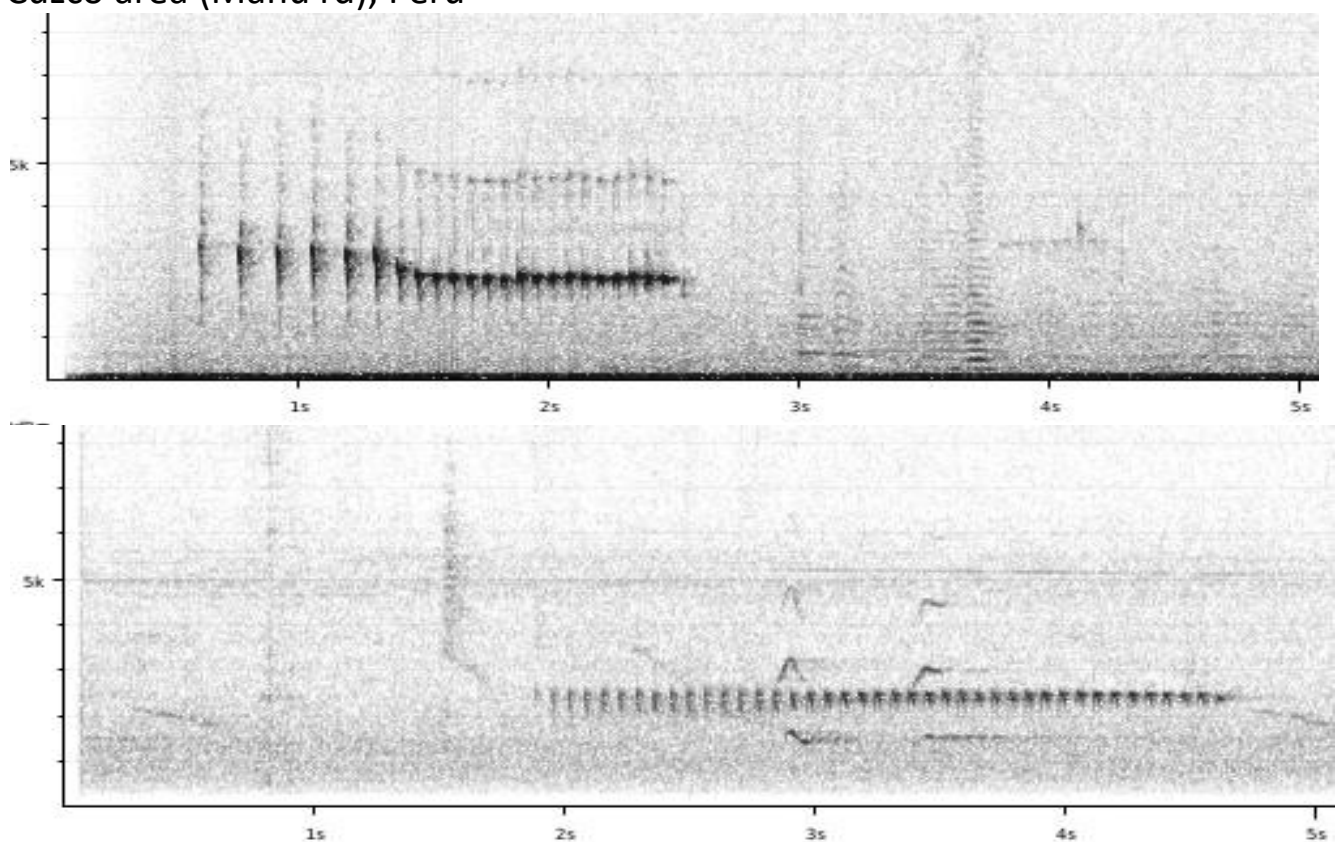

sticturus

No recordings for sure of this taxon. e.g. all recordings from Alta Floresta are very much like group 2.

Possibly this one from Noel Kempff NP (not particularly in bamboo)

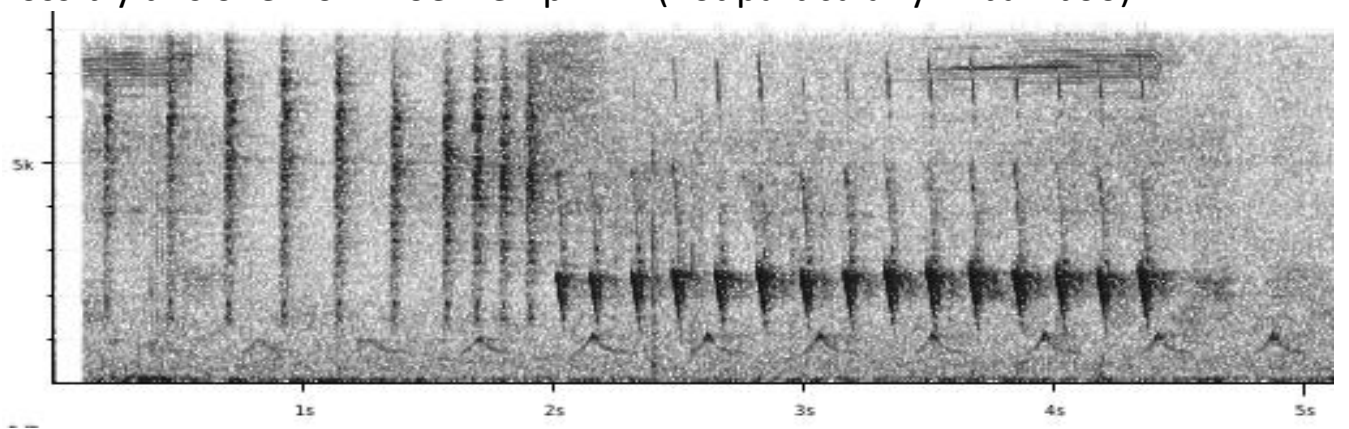



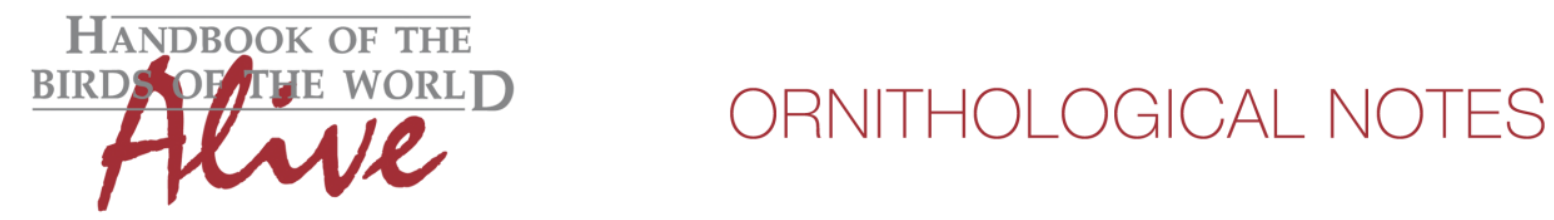

Typical song is a series of repeated notes. All races show quite some variation in song, but there are a few trends that become apparent:

Group 1: seldom sings at constant pitch (usually initially rising or falling). This group seems to have also an 'alternative song', consisting of two parts: a fast rattle followed by series of whistles.

Group 2: Typically sings at constant pitch. No alternative song has been documented (?).

Group 3: Difficult to draw conclusions, but it would seem that in SE Peru and E Bolivia, most recordings are of the 'alternative song' type. In SE Peru many of these, but not all, are recorded in bamboo. In Bolivia, no indication of association with bamboo is documented.

Group 1 and group 2 are thus vocally slightly different.

Group 3 needs more investigation, as there may be quite some confusion about which singing birds are actually obscurus/sticturus. If these indeed are a separate group occurring in a niche habitat, a possible vocal differentiation is that they evolved and utter mainly (or only) the alternative song, while apparently group 2 lost the ability to utter this alternative song. At present, this is obviously just speculation (e.g. we can't exclude that recordists simply associate the alternative song with this group, while this alternative song just occurs somewhat more in this region).

Needs further investigation!

This note was finalized on 7th October 2016, using sound recordings available on-line at that moment. We would like to thank in particular the many sound recordists who placed their recordings for this species on XC.

\section{References}

Tobias, J.A., Seddon, N., Spottiswoode, C.N., Pilgrim, J.D., Fishpool, L.D.C. \& Collar, N.J. (2010). Quantitative criteria for species delimitation. Ibis 152(4): 724-746.

\section{Recommended citation}

Boesman, P. (2016). Notes on the vocalizations of Long-billed Gnatwren (Ramphocaenus melanurus). HBW Alive Ornithological Note 436. In: Handbook of the Birds of the World Alive. Lynx Edicions, Barcelona. (retrieved from http://www.hbw.com/node/1284493 on 8 December 2016). 